\title{
Effects of Chlorinated Polypropylene on the Conformation of Polypropylene in Polypropylene/Chlorinated Polypropylene/Polyaniline Composites
}

\author{
Jianjun Chen, Yueyue Jia, Zhiye Zhang, Xinlong Wang, and Lin Yang \\ College of Chemical Engineering of Sichuan University, Chengdu, Sichuan 610065, China \\ Correspondence should be addressed to Xinlong Wang; wangxl@scu.edu.cn
}

Received 19 August 2014; Revised 13 October 2014; Accepted 20 October 2014

Academic Editor: Nikša Krstulović

Copyright (c) 2015 Jianjun Chen et al. This is an open access article distributed under the Creative Commons Attribution License, which permits unrestricted use, distribution, and reproduction in any medium, provided the original work is properly cited.

We investigated the changes in the conformation and crystalline structure of polypropylene (PP) using a combination of Fourier transform infrared spectroscopy (FTIR), wide-angle X-ray diffraction (WAXD), and differential scanning calorimetry (DSC) based on PP/chlorinated PP (CPP)/polyaniline (PANI) composites. The DSC heating thermograms and WAXD patterns of the $\mathrm{PP} / \mathrm{CPP} / \mathrm{PANI}$ composites showed that the $\beta$-crystal was affected greatly by the CPP content. Characterization of the specific regularity in the infrared band variation showed that the conformational orders of the helical sequences in PP exhibited major changes that depended on the CPP content. Initially, the intensity ratio of $A_{840} / A_{810}$ increased with the CPP concentration and reached its maximum level when the CPP content was $<13.22 \%$ before decreasing as the CPP content increased further. The effect of increased temperature on the conformation of PP was studied by in situ FTIR. Initially, the intensity ratio of $A_{999} / A_{973}$ decreased slowly with increasing the temperature up to $105^{\circ} \mathrm{C}$ before decreasing sharply with further increases in temperature and then decreasing slowly again when the temperature was higher than $128^{\circ} \mathrm{C}$.

\section{Introduction}

Conductive polymers are expected to yield attractive combinations of properties and are getting more and more attention for researchers from all over the world. Among conductive polymers, polyaniline has the best potential to become economically competitive, for its cheap materials, simple synthetic method, and stability in environment [1]. Although polyaniline has many merits, it is very difficult to be processed in usual methods used in conventional polymers due to its strong intermolecular and intramolecular interactions [2]. For these reasons, wide scale industrial application of polyaniline has been strongly impeded over several years. Many new protonating agents such as sulfonic acids, phosphoric acid esters [2,3], and phosphoric acid [4] have been introduced in recent years in order to improve the processability of polyaniline. To be worthy and mentioned, it was Cao et al. [5] that firstly introduced sulfonic acid as a protonating agent, and this made polyaniline possible to be processed in solvent. Another method to improve the processability of polyaniline was that polyaniline was blended with thermoplastic polymers due to polyaniline poor mechanical properties [4,6-8]. A unique specialty of this method lies in the combination of electric properties of polyaniline and mechanical properties of thermoplastic polymers.

In a series of previous studies, we have prepared $\mathrm{PP} / \mathrm{CPP} /$ PANI composites by melt processing, and investigated the influence of the concentration of $\mathrm{CPP}$ on the electric property of PP/CPP/PANI composites and the influence of CPP on the formation of the intermolecular and innermolecular hydrogen bond in the PP/CPP/PANI composites which is carefully proved by FTIR. We found that the hydrogen bond between CPP and PANI plays a prominent role in the decision of composites' electric property $[9,10]$. Does there exist a kind of interaction between CPP and PP in the $\mathrm{PP} / \mathrm{CPP} / \mathrm{PANI}$ composites? Hence, how to detect and identify the interaction between CPP and PP in the PP/CPP/PANI composites becomes one of the most important work. 
Since Natta et al. [11] first synthesized high molecular weight isotactic polypropylene (iPP) in 1955, the IR spectroscopy has been used to elucidate the structure of this crystalline polymer. In the infrared spectra of isotactic polypropylene, some absorption bands are connected with the intramolecular vibration coupling within a single chain, and this kind of band is defined as a regularity band or helix band $[12,13]$. Therefore, FTIR spectroscopy can provide much meaningful structural information and it is an effective method of denoting the changes of helical conformation of PP $[14,15]$. During the past decades, it has been well established that specific regularity bands are related to the different critical length " $n$ " of isotactic sequences [16-18]. For example, the minimum $n$ values for appearance of bands at $973,998,841$, and $1220 \mathrm{~cm}^{-1}$ are $5,10,12$, and 14 monomer units in helical sequences, respectively. Zhu et al. [17] adopted in situ FTIR and arranged the various regularity bands in terms of the order degree from high to low: 940, 1220, 1167, $1303,1330,841,998,900,808,1100$, and $973 \mathrm{~cm}^{-1}$. Hence, the information of effects of CPP on the conformation of PP can be obtained by calculating the absorbance ratios of different regularity bands in FTIR spectra. It has been reported that, for iPP samples when the fully isotactic sequences are very short, iPP crystallizes in the $\gamma$ form, whereas very long regular isotactic sequences generally crystallize only in the $\alpha$ form [19-23]. Therefore, the crystal structure is greatly affected by the helical conformation regularity.

In this investigation, DSC, WAXD and FTIR are adopted to detect and identify the interaction between CPP and PP in the PP/CPP/PANI composites. The variation of conformation and crystalline structure of PP has been discussed. Conductive polymers are expected to yield attractive combinations of properties, and they are gaining increasing attention from researchers throughout the world. In particular, polyaniline (PANI) is considered to have the highest potential to become an economically competitive conductive polymer due to the cheap materials required for its production, simple synthetic method, and environmental stability [1]. Although PANI has many merits, it is very difficult to process with the standard methods used for conventional polymers because of its strong intermolecular and intramolecular interactions [2]. Thus, large-scale industrial applications of PANI have been hindered for several years. However, many new protonating agents such as sulfonic acid, phosphoric acid esters [2,3], and phosphoric acid [4] have been employed in recent years to improve the processability of PANI. It should be mentioned that Cao et al. [5] were the first to introduce sulfonic acid as a protonating agent, thereby allowing PANI to be processed in a solvent. Another method for improving the processability of PANI is blending with thermoplastic polymers, which due to the poor mechanical properties of PANI $[4,6-8]$. A unique feature of this method is the combination of the electric properties of PANI and mechanical properties of thermoplastic polymers.

In a series of previous studies, we prepared polypropylene (PP)/chlorinated PP (CPP)/PANI composites by melt processing and investigated the effects of the CPP concentration on the electric properties of PP/CPP/PANI composites, as well as the influence of CPP on the formation of intermolecular and intramolecular hydrogen bonds in the $\mathrm{PP} / \mathrm{CPP} / \mathrm{PANI}$ composites, which were carefully examined by Fourier transform infrared spectroscopy (FTIR). We found that the hydrogen bonds between CPP and PANI have a major role in determining the electric properties of composites $[9,10]$. However, there may also be important interactions between CPP and PP in PP/CPP/PANI composites. Thus, detecting and identifying the interactions between CPP and $\mathrm{PP}$ in $\mathrm{PP} / \mathrm{CPP} / \mathrm{PANI}$ composites has become a major focus of our research.

In this study, we used differential scanning calorimetry (DSC), wide-angle X-ray diffraction (WAXD), and FTIR to detect and identify the interactions between CPP and PP in $\mathrm{PP} / \mathrm{CPP} / \mathrm{PANI}$ composites. We discuss the variations in the conformations and crystalline structure of PP.

\section{Experimental}

2.1. Materials. PANI protonated with $\mathrm{HCl}$ was supplied by Chengdu Organic Chemicals Co., Ltd. (China) and its electrical conductivity was $\mathrm{ca} 1 \mathrm{~S} \mathrm{~cm}^{-1}$. PANI was synthesized using the air oxidation method (China patent: CN1626564A). The granularity of PANI-HCl was about $30 \mu \mathrm{M}$.

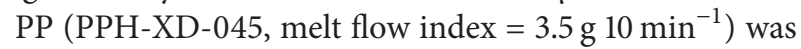
supplied by PetroChina Co., Ltd. (China).

Dodecylbenzenesulfonic acid (DBSA) was supplied by Kewei Chemicals Co., Ltd. (China) and its content was about 96\% (wt).

CPP was supplied by Sichuan Weiye Chemicals Co., Ltd. (China) and its chlorine content was about $31 \%$ (wt).

2.2. Preparation of Composites. PANI protonated with $\mathrm{HCl}$ was neutralized with $20 \%(\mathrm{wt})$ sodium hydroxide $(\mathrm{NaOH})$ aqueous solution for $48 \mathrm{~h}$ (the $\mathrm{NaOH}$ aqueous solution was in great excess compared with the amount of PANI-HCl) where the $\mathrm{pH}$ of the blend (i.e., $\mathrm{PANI}-\mathrm{HCl}$ and $\mathrm{NaOH}$ aqueous solution) was ca 11, which was followed by filtration and washing with deionized water until the $\mathrm{pH}$ of percolate was 6-8. The polyemeraldine base $\left(\mathrm{PANI}_{\mathrm{emer}}\right)$ obtained was dried under vacuum. The purified and dried $\mathrm{PANI}_{\mathrm{emer}}$ was blended with DBSA, where the molar ratio of DBSA relative to $\mathrm{PANI}_{\mathrm{emer}}$ was 0.5 . The blend was stirred for $48 \mathrm{~h}$ at ambient temperature, thereby obtaining PANI protonated with DBSA (PANI-DBSA).

The PP/CPP/PANI composites were prepared on a tworoll mill. The compositions of the blends are shown in Table 1.

2.3. FTIR Measurement. The specimens used to obtain FTIR measurements were molded into very thin films. Compression molding was performed in the following conditions: preheating at $180^{\circ} \mathrm{C}$ for $5 \mathrm{~min}$ at low pressure and compression for $10 \mathrm{~min}$ at $15 \mathrm{MPa}$ at the same temperature, followed by cooling in the mold to ambient temperature with a cooling rate of $30^{\circ} \mathrm{C} \mathrm{min}^{-1}$ at $15 \mathrm{MPa}$. FTIR analysis was conducted using a Nicolet 170X FTIR spectrometer (Nicolet Co., USA) at a resolution of $2 \mathrm{~cm}^{-1}$. For in situ FTIR, the spectra were obtained at elevated temperatures using a miniature heat controller. The spectrum was collected every $30 \mathrm{~s}$ and a heating rate of $5^{\circ} \mathrm{C} \mathrm{min}^{-1}$ was employed. The temperature was 
TABLE 1: Formation of PP/PANI composition (in wt \%).

\begin{tabular}{lccccc}
\hline Sample code & PP & PANI $_{\text {emer }}$ & DBSA & CPP & $\begin{array}{c}\text { Theoretical } \\
\text { degree of } \\
\text { protonation }\end{array}$ \\
\hline PP/PANI 1 & 87.23 & 4.10 & 7.79 & 0.88 & 0.5 \\
PP/PANI 2 & 83.70 & 4.10 & 7.79 & 4.41 & 0.5 \\
PP/PANI 3 & 79.30 & 4.10 & 7.79 & 8.81 & 0.5 \\
PP/PANI 4 & 74.89 & 4.10 & 7.79 & 13.22 & 0.5 \\
PP/PANI 5 & 70.49 & 4.10 & 7.79 & 17.62 & 0.5 \\
\hline
\end{tabular}

monitored using a copper-constantan thermocouple, which was placed directly on the sample. During detection, the specimen was protected by nitrogen.

2.4. DSC. The calorimetric measurements of all samples were obtained using a NETZSCH DSC 204 at a scan rate of $10^{\circ} \mathrm{C} \mathrm{min}^{-1}$ under a flowing nitrogen atmosphere, and the sample weight was ca $10 \mathrm{mg}$.

2.5. Wide-Angle X-Ray Diffraction. WAXD investigations were performed using a DX-2500 SSC diffractometer (China) in the reflection mode. $\mathrm{Cu} \mathrm{K} \alpha$ radiation was used at $40 \mathrm{kV}$ and $25 \mathrm{~mA}$. The scan step was $0.06^{\circ}$ (in $2 \theta$ ) with a period of $2 \mathrm{~s}$ per step. The $\beta$-crystal content was deduced from the X-ray data according to standard procedures [24] using the relationship:

$$
k=\frac{H_{\beta(300)}}{H_{\beta(300)}+H_{\alpha(110)}+H_{\alpha(040)}+H_{\alpha(130)}},
$$

where $H_{\alpha}(h k l)$ and $H_{\beta}(h k l)$ represent the heights of the $(h k l)$ peak for the $\alpha$ and $\beta$ phases, respectively.

\section{Results and Discussion}

3.1. Effect of CPP on the Crystal Structure of PP. Figure 1 shows the DSC heating thermograms for PP/CPP/PANI blends, which were recorded at a heating rate of $10^{\circ} \mathrm{C} \mathrm{min}^{-1}$. In order to clearly demonstrate the differences in the DSC curves, only two curves are shown in Figure 1. The two samples produced melting endotherms with characteristic doublet peaks. The peak at the lower temperature is represented as a shoulder of the peak at the higher temperature. The multiple peaks in the DSC curves are attributable to the melting of the two polymorphic forms of PP [25]. In general, the $\beta$ form melted at a lower temperature and the $\alpha$ form melted at a higher temperature. Figure 1 also shows clearly that the $\beta$ peak of PP/PANI 4 is more prominent than that of $\mathrm{PP} / \mathrm{PANI} 2$. This demonstrates that the $\beta$-crystal is affected greatly by the CPP content.

Figure 2 shows the WAXD patterns for the PP/CPP/PANI composites. PP is crystallizable and it has three crystalline phase types: $\alpha$-crystal, $\beta$-crystal, and $\gamma$-crystal. In Figure 2 , the presence of $\alpha$-crystal is indicated by the crystalline peaks at ca $14^{\circ}, 17^{\circ}, 18.5^{\circ}, 21^{\circ}$, and $21.8^{\circ}$, while the crystalline peak at ca $16^{\circ}$ is attributed to $\beta$-crystal [25]. According to the standard procedures [24], the $\beta$-PP contents are $12.7 \%$ and $27.7 \%$ for $\mathrm{PP} / \mathrm{PANI} 1$ and PP/PANI 4, respectively, thereby indicating

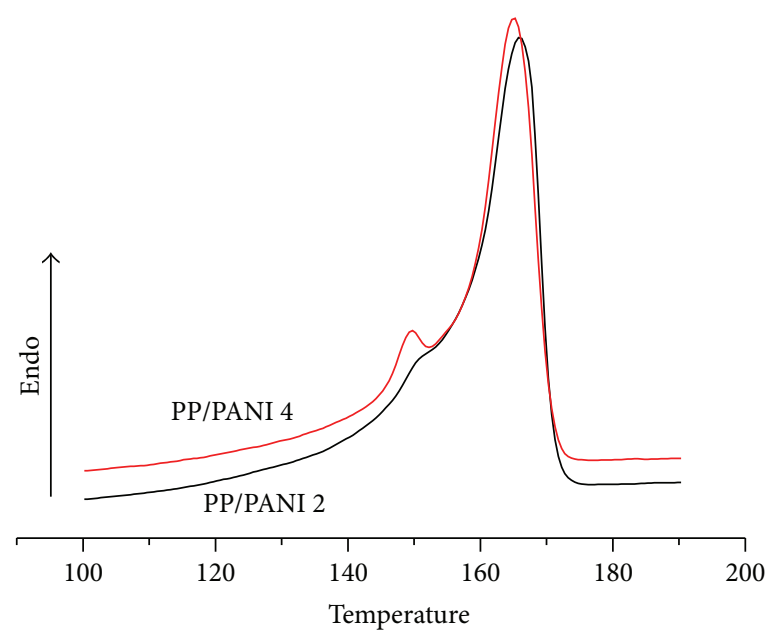

FIGURE 1: DSC heating thermograms of PP/CPP/PANI blends.

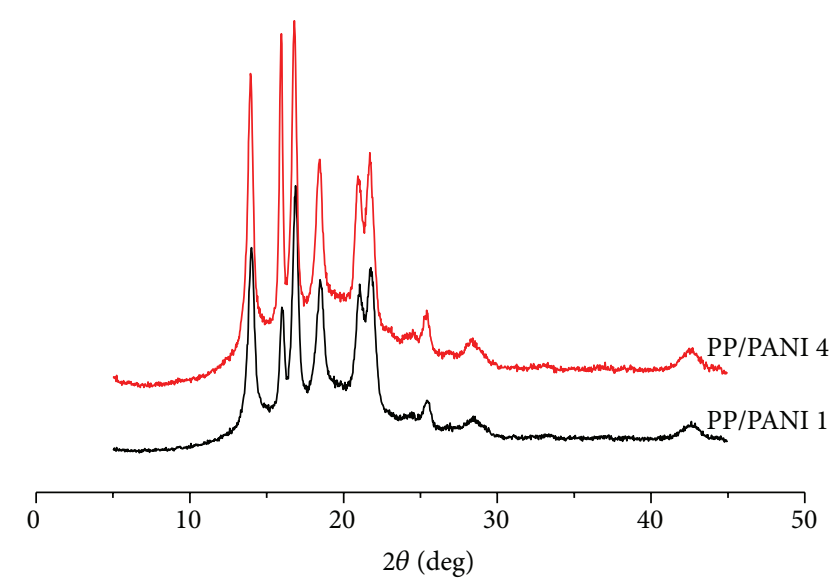

FIgURE 2: WAXD patterns of PP/PANI 1 and PP/PANI 4.

that the CPP content has a major impact on the $\beta$-crystal type. These results are consistent with those obtained by DSC.

3.2. Effect of the CPP Content on the Conformation Structure of $P P$. In general, the regularity bands of $P P$ are related to the different helical lengths " $n$ " of the isotactic sequences [15-17]. The intensity of the regularity bands can reflect the quantity of different helical lengths " $n$ " in isotactic sequences. Therefore, the conformational ordering of different samples can be determined based on the absorbance ratios of the various regularity bands.

Figure 3 shows the FTIR spectra of the PP/CPP/PANI composites with different CPP contents, which demonstrate that the intensities of different regularity bands (810, 840, 973 , and $999 \mathrm{~cm}^{-1}$ ) changed slightly as the CPP concentration increased. The variations in these regularity bands indicate that the conformation of PP is affected by the CPP concentration. These regularity bands can be divided into two groups $\left(810 / 40 \mathrm{~cm}^{-1}\right.$ and $\left.973 / 999 \mathrm{~cm}^{-1}\right)$, which we will discuss in detail later. 


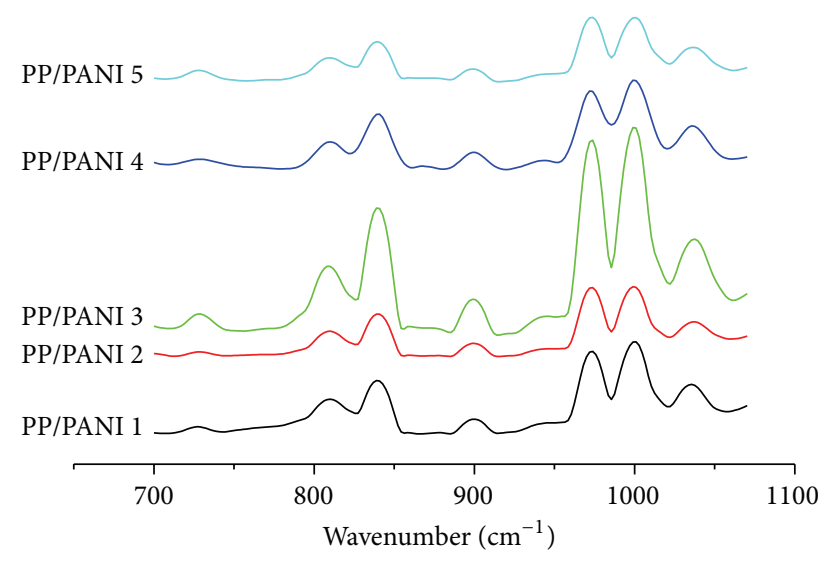

FIGURE 3: FTIR spectra of the PP/CPP/PANI composites.

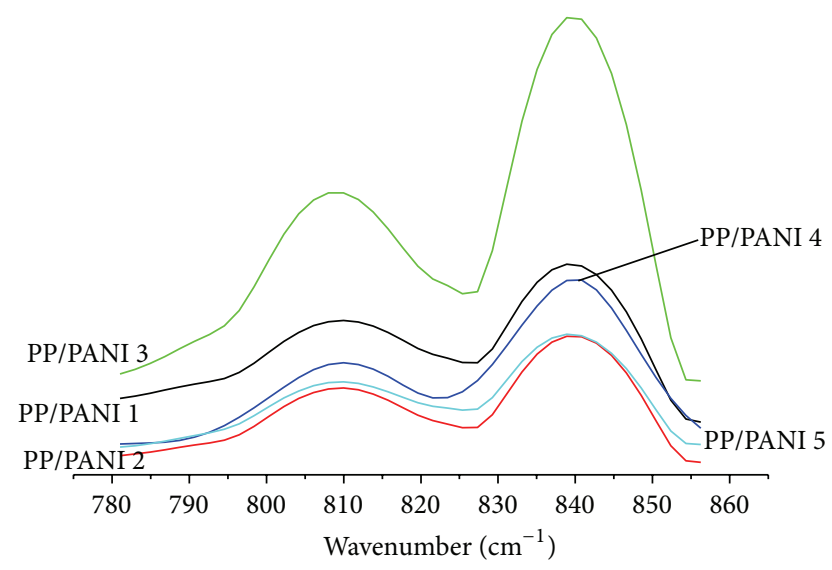

FIGURE 4: FTIR spectra of the PP/CPP/PANI composites with different CPP concentrations $\left(780-856 \mathrm{~cm}^{-1}\right)$.

3.2.1. The Region $\left(780-856 \mathrm{~cm}^{-1}\right)$ of the FTIR Spectra. Figure 4 shows the FTIR spectra in the $780-856 \mathrm{~cm}^{-1}$ region for the PP/CPP/PANI composites with different CPP contents. Obviously, there are two Gaussian bands in this region, where the first band is at around $810 \mathrm{~cm}^{-1}$ and the second band is at around $840 \mathrm{~cm}^{-1}$ for all of the PP/CPP/PANI composites. In general, the intensity of the two bands was closely related to the size of the two critical lengths " $n$ " for isotactic sequences of PP. Each FTIR band has its own intensity coefficient and each sample has its own thickness; thus, the intensities of the regular helical conformation bands should be processed in order to determine the effect of the CPP content. In the present study, the variation in the intensity ratio was used to indicate the effect of the CPP content on the two critical lengths " $n$ " for isotactic sequences of PP.

The FTIR results for this region are shown in Table 2, where $\mathrm{XS}_{810}=A_{810} /\left(A_{810}+A_{840}\right)$ and $\mathrm{XS}_{840}=A_{840} /\left(A_{810}+\right.$ $\left.A_{840}\right)$. The relationship between the $A_{840} / A_{810}$ ratio and the CPP content is shown in Figure 5.

Table 2 and Figure 5 show that the appearances of bands at $840 / 810 \mathrm{~cm}^{-1}$ for the two critical lengths " $n$ " of isotactic sequences were affected by the CPP content. The $A_{840} / A_{810}$
TABLE 2: Curve-fitting results for spectra of the region (780$856 \mathrm{~cm}^{-1}$ ).

\begin{tabular}{lcccccc}
\hline \multirow{2}{*}{ Sample code } & \multicolumn{3}{c}{ First band } & \multicolumn{3}{c}{ Second band } \\
& $\nu 1 \mathrm{~cm}^{-1}$ & $A_{810}$ & $\mathrm{XS}_{810}$ & $\nu 2 \mathrm{~cm}^{-1}$ & $A_{840}$ & $\mathrm{XS}_{840}$ \\
\hline PP/PANI 1 & 809.9 & 1.137 & 0.546 & 840.1 & 0.944 & 0.454 \\
PP/PANI 2 & 809.8 & 0.669 & 0.453 & 839.9 & 0.807 & 0.547 \\
PP/PANI 3 & 809.3 & 1.753 & 0.421 & 839.9 & 2.410 & 0.579 \\
PP/PANI 4 & 809.8 & 0.697 & 0.362 & 839.7 & 1.229 & 0.638 \\
PP/PANI 5 & 810.1 & 0.671 & 0.458 & 839.8 & 0.794 & 0.542 \\
\hline
\end{tabular}

v: wavenumber; $A$ : intensity; XS: percent of $A$.

ratio determined the ratio of the two critical lengths " $n$ " of isotactic sequences. The critical length " $n$ " of isotactic sequences was larger for the second band than for the first band. Apparently, the order degree was higher when the ratio was larger. As shown in Figure 5, the $A_{840} / A_{810}$ ratio increased initially with the CPP content and it reached a maximum when the CPP content was $13.22 \%$, after which it decreased as the CPP content increased further. Thus, the critical length " $n$ " of the isotactic sequences with a band at $840 \mathrm{~cm}^{-1}$ corresponded to that with a band at $810 \mathrm{~cm}^{-1}$, which increased with the CPP content up to $13.22 \%$ before decreasing as the CPP content increased further. These results indicate that the conformational structures or the order degrees of the helical sequences of PP were affected significantly by the CPP content. This may be attributable to interactions between CPP and the PP matrix.

3.2.2. The Region (950-1020 $\left.\mathrm{cm}^{-1}\right)$ of the FTIR Spectra. Figure 6 shows the FTIR spectra in the $950-1020 \mathrm{~cm}^{-1}$ region for the PP/CPP/PANI composites with different CPP contents, which demonstrates that there are two Gaussian bands in this region, where the first band is at around $973 \mathrm{~cm}^{-1}$ and the second band is at around $999 \mathrm{~cm}^{-1}$. The critical length " $n$ " values of the isotactic sequences for the appearance of bands at 973 and $999 \mathrm{~cm}^{-1}$ were $2-4$ and 5-10 monomer units in the helical sequences, respectively [13]. The intensities of the two bands are shown in Table 3.

In Table 3, $\mathrm{XS}_{973}=A_{973} /\left(A_{973}+A_{999}\right)$ and $\mathrm{XS}_{999}=$ $A_{999} /\left(A_{973}+A_{999}\right)$. The $A_{999} / A_{973}$ ratio determines the ratio of the two critical lengths " $n$ " of isotactic sequences. The relationship between the $A_{999} / A_{973}$ ratio and CPP content is shown in Figure 7.

Table 3 and Figure 7 show the effects of the CPP content on the $A_{999} / A_{973}$ ratio. Figure 7 demonstrates that the $A_{999} / A_{973}$ ratio changed slightly with different CPP contents, which shows that the critical length " $n$ " of isotactic sequences for the appearance of a band at $999 \mathrm{~cm}^{-1}$, which corresponded to that for the appearance of a band at $973 \mathrm{~cm}^{-1}$, was affected slightly by the CPP content.

3.3. Effect of Temperature on the Conformation Structure of $P P$ in the PP/CPP/PANI Composite. The crystallization of $\mathrm{PP}$ composites is usually affected significantly by the process temperature. Thus, to investigate the influence of temperature 


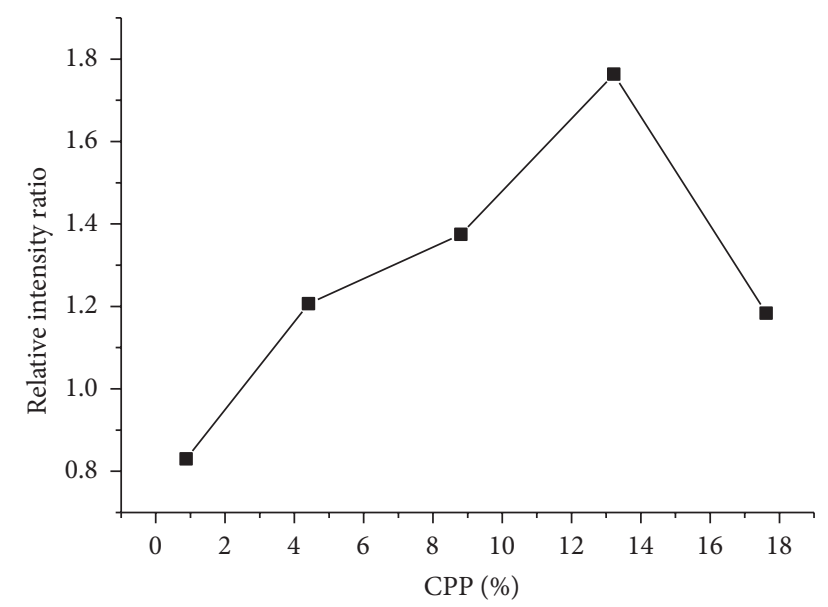

FIgURE 5: The relation between the ratio of $A_{840} / A_{810}$ and CPP content.

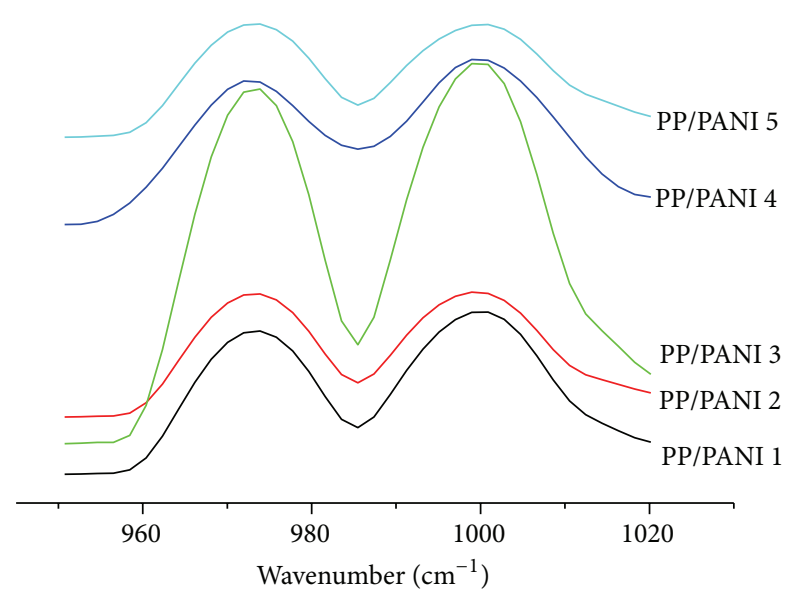

FIGURE 6: FTIR spectra of the PP/CPP/PANI composites with different CPP concentrations $\left(950-1020 \mathrm{~cm}^{-1}\right)$.

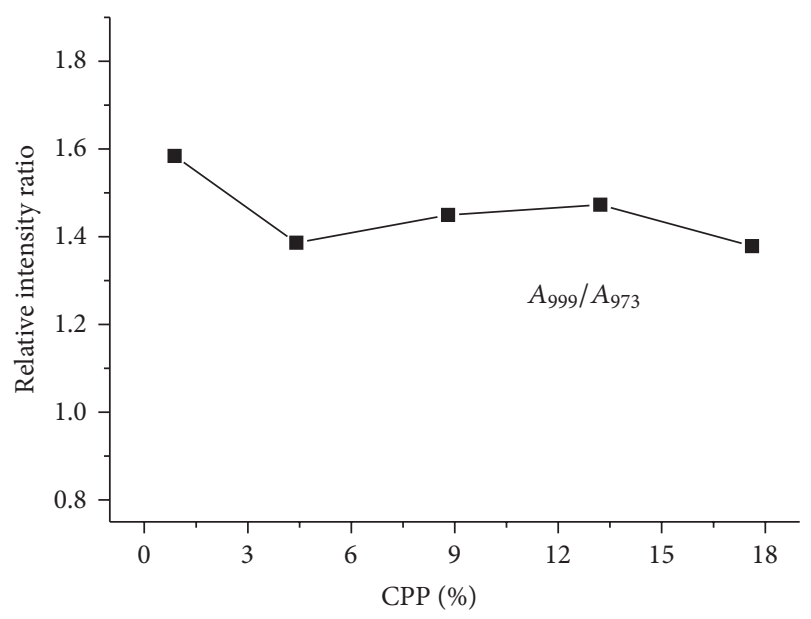

Figure 7: The relation between the ratio $\left(A_{999} / A_{973}\right)$ and CPP content.

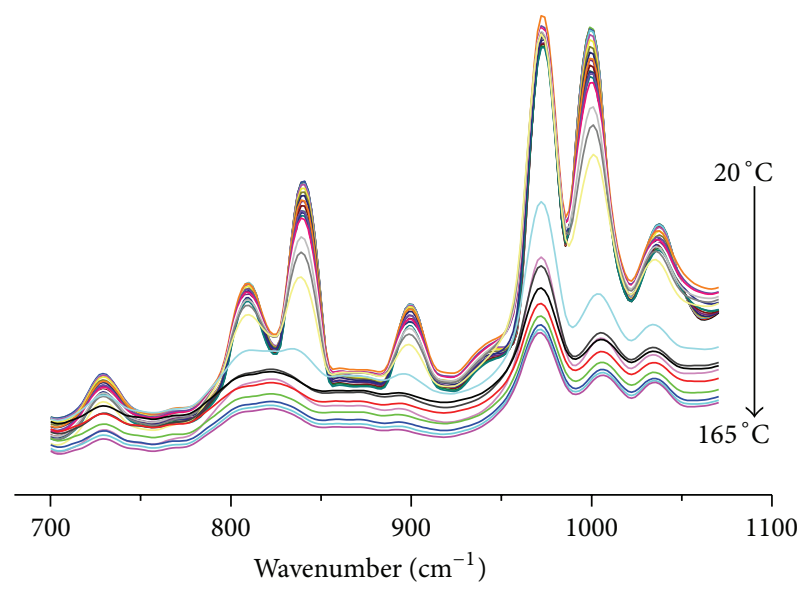

FIGURE 8: FTIR spectra of PP/PANI 4 at different temperatures.

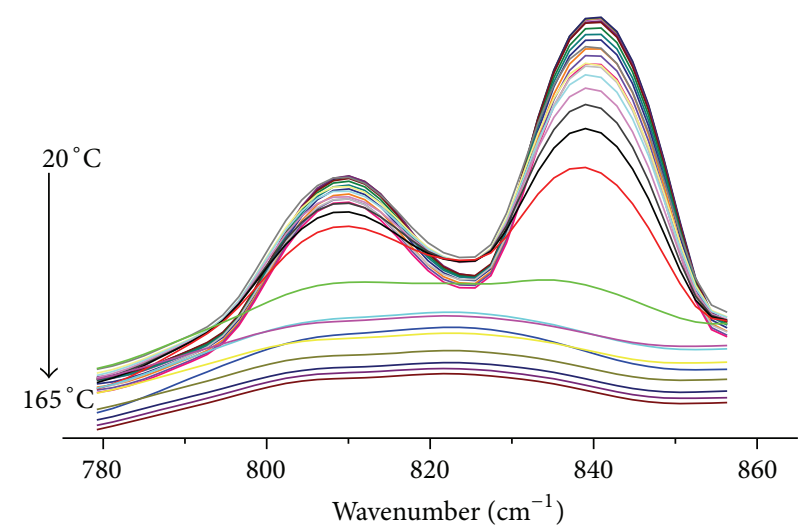

FIGURE 9: FTIR spectra of PP/PANI 4 at different temperatures $\left(780-856 \mathrm{~cm}^{-1}\right)$.

on the conformation of PP, the PP/PANI 4 sample was analyzed by in situ FTIR.

Figure 8 shows the FTIR spectra of PP/PANI 4 at different temperatures. There are several regularity bands in spectra that changed slightly with the increasing temperature in the composite such as $810,840,973$, and $999 \mathrm{~cm}^{-1}$, which indicates that the conformation structure of PP is influenced by temperature. Two regions included four regularity bands $\left(810,840,973\right.$, and $\left.999 \mathrm{~cm}^{-1}\right)$ will be discussed in detail later. Figure 8 shows the FTIR spectra of PP/PANI 4 at different temperatures. Several regularity bands in the spectra changed slightly as the temperature increased, such as $810,840,973$, and $999 \mathrm{~cm}^{-1}$, which indicates that the conformation of PP is affected by the temperature. Two regions included four regularity bands $\left(810,840,973\right.$, and $\left.999 \mathrm{~cm}^{-1}\right)$, which will be discussed in detail later.

3.3.1. The Region $\left(780-856 \mathrm{~cm}^{-1}\right)$ of the FTIR Spectra of $P P / P A N I$ 4. Figure 9 shows the FTIR spectra in the $780-$ $856 \mathrm{~cm}^{-1}$ region for PP/PANI 4 at different temperatures, which demonstrates that there are two Gaussian bands at around $810 \mathrm{~cm}^{-1}$ and $840 \mathrm{~cm}^{-1}$. Since the intensity of the 


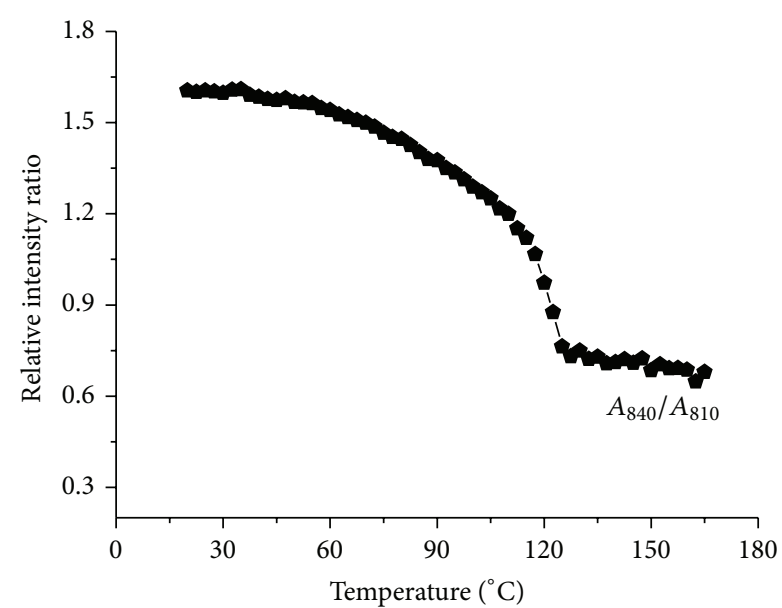

FIGURE 10: Intensity ratio $\left(A_{840} / A_{810}\right)$ of regularity bands versus temperatures.

TABLE 3: Curve-fitting results for spectra of the region (950$1020 \mathrm{~cm}^{-1}$ ).

\begin{tabular}{lcccccc}
\hline \multirow{2}{*}{ Sample code } & \multicolumn{3}{c}{ First band } & \multicolumn{3}{c}{ Second band } \\
& $\nu 1 \mathrm{~cm}^{-1}$ & $A_{973}$ & $\mathrm{XS}_{973}$ & $v 2 \mathrm{~cm}^{-1}$ & $A_{999}$ & $\mathrm{XS}_{999}$ \\
\hline PP/PANI 1 & 973.1 & 1.288 & 0.392 & 998.1 & 1.993 & 0.608 \\
PP/PANI 2 & 972.8 & 1.101 & 0.424 & 999.2 & 1.494 & 0.576 \\
PP/PANI 3 & 972.7 & 3.177 & 0.412 & 998.9 & 4.537 & 0.588 \\
PP/PANI 4 & 972.7 & 1.442 & 0.408 & 999.0 & 2.089 & 0.592 \\
PP/PANI 5 & 972.5 & 1.028 & 0.426 & 999.3 & 1.385 & 0.574 \\
\hline
\end{tabular}

two bands is related closely to the size of the two critical lengths " $n$ " of isotactic sequences of PP, the relative ratio of the intensity of the two bands can be used to represent the helical conformation of PP.

Figure 10 shows the relationship between the intensity ratio of the regularity bands at 810 and $840 \mathrm{~cm}^{-1}$ and temperature, which demonstrates that the $A_{840} / A_{810}$ ratio decreased slowly initially as the temperature increased to $105^{\circ} \mathrm{C}$, but it decreased sharply as the temperature increased further before decreasing slowly again when the temperature exceeded $125^{\circ} \mathrm{C}$. Furthermore, the size of the critical lengths " $n$ " of isotactic sequences related to the appearance of a band at $840 \mathrm{~cm}^{-1}$, which corresponded to that for the appearance of a band at $810 \mathrm{~cm}^{-1}$, decreases slowly initially as the temperature increased up to $105^{\circ} \mathrm{C}$, but it decreased sharply as the temperature increased further before decreasing slowly again when the temperature exceeded $125^{\circ} \mathrm{C}$. These results indicate that the ordered regularity of PP decreased as the temperature increased. This may be attributable to differences in the behavior of the amorphous or partly ordered zones of $\mathrm{PP}$ at different temperatures.

3.3.2. The Region $\left(940-1020 \mathrm{~cm}^{-1}\right)$ of the FTIR spectra of $P P / P A N I 4$. Figure 11 shows the FTIR spectra of the 940$1020 \mathrm{~cm}^{-1}$ region for PP/PANI 4 at different temperatures, which demonstrates that there are two Gaussian bands at around $973 \mathrm{~cm}^{-1}$ and $999 \mathrm{~cm}^{-1}$. Similar to the bands at

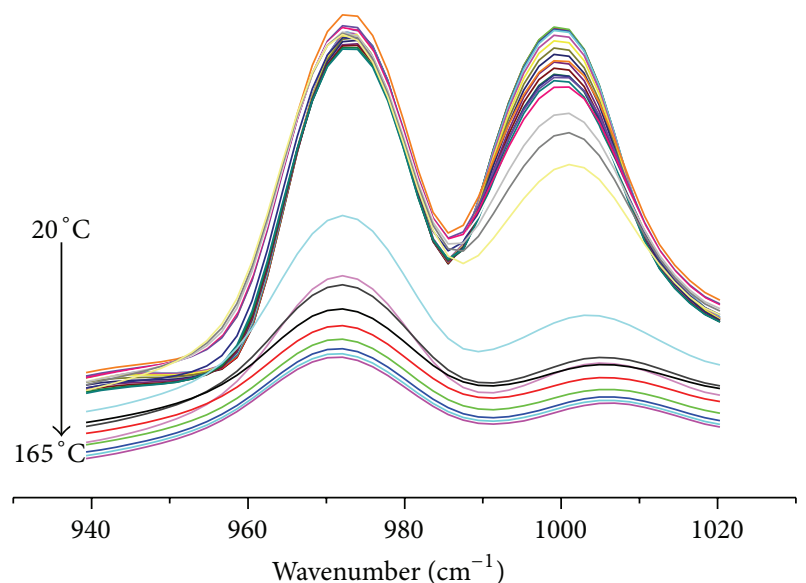

FIGURE 11: FTIR spectra of PP/PANI 4 at different temperatures $\left(940-1020 \mathrm{~cm}^{-1}\right)$.

$810 \mathrm{~cm}^{-1}$ and $840 \mathrm{~cm}^{-1}$, the $A_{999} / A_{973}$ intensity ratio can be used to represent the order degree of the PP composites.

Figure 12 shows the $A_{999} / A_{973}$ intensity ratio versus temperature, which demonstrates that the $A_{999} / A_{973}$ ratio generally decreased as the temperature increased. The $A_{999} / A_{973}$ ratio decreased slowly initially as the temperature increased up to $105^{\circ} \mathrm{C}$, but it decreased sharply as the temperature increased further before decreasing slowly again as the temperature exceeded $128^{\circ} \mathrm{C}$. The relationship between the conformational ordering of the helical sequences of PP and temperature was determined from the relationship between the $A_{999} / A_{973}$ ratio and temperature. The order degree decreased slowly initially as the temperature increased up to $105^{\circ} \mathrm{C}$, but it decreased sharply as the temperature increased further before decreasing slowly again subsequently. This may be attributable to differences in the behavior of the different ordered zones as the temperature increased. These results were consistent with the relationship between the $A_{840} / A_{810}$ intensity ratio and temperature.

\section{Conclusions}

The analysis of the DSC heating thermograms and WAXD patterns of the PP/CPP/PANI composites showed that the $\beta$ crystal was affected greatly by the CPP content. Furthermore, the crystal structure was affected by the regularity of the helical conformation. FTIR was used to investigate the effects of the CPP content and temperature on the conformation of $\mathrm{PP}$ in the PP/CPP/PANI composites, which showed that four regularity bands $\left(810,840,973\right.$, and $\left.999 \mathrm{~cm}^{-1}\right)$ were related to different critical lengths " $n$ " of the isotactic sequences of PP. The results obtained in this study suggest the following conclusions.

(i) The $A_{840} / A_{810}$ intensity ratio increased initially with the CPP concentration and reached its maximum when the CPP content was lower than $13.22 \%$ before decreasing as the CPP content increased further. Thus, the $A_{999} / A_{973}$ ratio was affected slightly by the CPP content. 


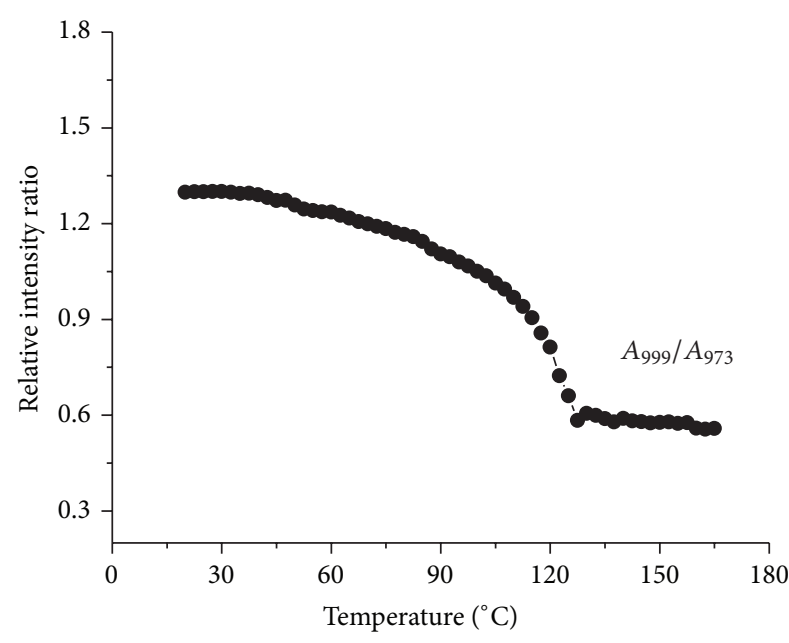

Figure 12: The relation between intensity ratio $\left(A_{999} / A_{973}\right)$ and temperature.

(ii) The $A_{840} / A_{810}$ intensity ratio decreased slowly initially as the temperature increased up to $105^{\circ} \mathrm{C}$, but it decreased sharply as the temperature increased further before decreasing slowly again when the temperature exceeded $125^{\circ} \mathrm{C}$, where the $A_{999} / A_{973}$ intensity ratio was similar to $A_{840} / A_{810}$.

\section{Conflict of Interests}

The authors declare that there is no conflict of interests regarding the publication of this paper.

\section{References}

[1] A. G. MacDiarmid, "Polyaniline and polypyrrole: where are we headed?” Synthetic Metals, vol. 84, no. 1-3, pp. 27-34, 1997.

[2] W. Łuzny, T. Kaniowski, and A. Proń, "Structural and transport properties of thermally processable conducting polymer: polyaniline protonated with diphenyl phosphate," Polymer, vol. 39, no. 2, pp. 475-483, 1998.

[3] A. Pron, W. Luzny, and J. Laska, "Thermally processable polyaniline protonated with diphenyl phosphate-preparation and structural aspects," Synthetic Metals, vol. 80, no. 2, pp. 191$193,1996$.

[4] R. Fryczkowski, C. Ślusarczyk, and J. Fabia, "Structure and conducting properties of thermoplastic composites of polypropylene and polyaniline protonated in solid state," Synthetic Metals, vol. 156, no. 2-4, pp. 310-317, 2006.

[5] Y. Cao, P. Smith, and A. J. Heeger, "Counter-ion induced processibility of conducting polyaniline and of conducting polyblends of polyaniline in bulk polymers," Synthetic Metals, vol. 48, no. 1, pp. 91-97, 1992.

[6] J. Laska, K. Zak, and A. Pron, "Conducting blends of polyaniline with conventional polymers," Synthetic Metals, vol. 84, no. 1-3, pp. 117-118, 1997.
[7] J. Laska, A. Pron, M. Zagorska, S. Lapkowski, and S. Lefrant, "Thermally processable conducting polyaniline," Synthetic Metals, vol. 69, no. 1-3, pp. 113-115, 1995.

[8] P. Passiniemi, J. Laakso, H. Osterholm, and M. Pohl, "TEM and WAXS characterization of polyaniline/PP fibers," Synthetic Metals, vol. 84, no. 1-3, pp. 775-776, 1997.

[9] L. Yang, J. Y. Chen, and H. L. Li, "Investigation on the microstructure and the electric property of poly(propylene)/ chlorinated poly(propylene)/poly(aniline) composites," Journal of Applied Polymer Science, vol. 111, no. 2, pp. 988-997, 2009.

[10] L. Yang, J. Y. Chen, and H. L. Li, "Effects of chlorinated polypropylene on the hydrogen-bond and electric property of polypropylene/chlorinated polypropylene/polyaniline composites: FTIR analysis," Polymer Engineering \& Science, vol. 49, no. 3, pp. 462-470, 2009.

[11] G. Natta, P. Plno, P. Corradini et al., "Crystalline high polymers of $\alpha$-olefin," Journal of the American Chemical Society, vol. 77, no. 6, pp. 1708-1710, 1955.

[12] G. Zerbi, F. Ciampelli, and V. Zamboni, "Classification of crystallinity bands in the infrared spectra of polymers," Journal of Polymer Science Part C, vol. 7, no. 1, pp. 141-151, 1964.

[13] M. Kobayashi, K. Akita, and H. Tadokoro, "Infrared spectra and regular sequence lengths in isotactic polymer chains," Die Makromolekulare Chemie, vol. 118, no. 1, pp. 324-342, 1968.

[14] Y. V. Kissin and L. A. Rishina, "Regularity bands in the i.r. spectra of C3H6C3D6 copolymers," European Polymer Journal, vol. 12, no. 10, pp. 757-759, 1976.

[15] Z. Su, H. Wang, J. Dong et al., "Conformation transition and crystalline phase variation of long chain branched isotactic polypropylenes (LCB-iPP)," Polymer, vol. 48, no. 3, pp. 870-876, 2007.

[16] L. A. Hanna, P. J. Hendra, W. Maddams, H. A. Willis, V. Zichy, and M. E. A. Cudby, "Vibrational spectroscopic study of structural changes in isotactic polypropylene below the melting point," Polymer, vol. 29, no. 10, pp. 1843-1847, 1988.

[17] X. Zhu, D. Yan, H. Yao, and P. Zhu, "In situ FTIR spectroscopic study of the regularity bands and partial-order melts of isotactic poly(propylene)," Macromolecular Rapid Communications, vol. 21, no. 7, pp. 354-357, 2000.

[18] X. Zhu, Y. Fang, and D. Yan, "A possible explanation to the structure change of isotactic polypropylene occurring at about $135^{\circ}$ C," Polymer, vol. 42, no. 21, pp. 8595-8598, 2001.

[19] R. G. Alamo, M. H. Kim, M. J. Galante, J. R. Isasi, and L. Mandelkern, "Structural and kinetic factors governing the formation of the $\gamma$ polymorph of isotactic polypropylene," Macromolecules, vol. 32, no. 12, pp. 4050-4064, 1999.

[20] R. G. Alamo, D. L. VanderHart, M. R. Nyden, and L. Mandelkern, "Morphological partitioning of ethylene defects in random propylene-ethylene copolymers," Macromolecules, vol. 33, no. 16, pp. 6094-6105, 2000.

[21] D. L. VanderHart, R. G. Alamo, M. R. Nyden, M. H. Kim, and L. Mandelkern, "Observation of resonances associated with stereo and regio defects in the crystalline regions of isotactic polypropylene: toward a determination of morphological partitioning," Macromolecules, vol. 33, no. 16, pp. 6078-6093, 2000.

[22] R. Thomann, C. Wang, J. Kressler, and R. Muelhaupt, "On the $\gamma$-phase of isotactic polypropylene," Macromolecules, vol. 29, no. 26, pp. 8425-8434, 1996.

[23] R. Thomann, H. Semke, R.-D. Maier et al., "Influence of stereoirregularities on the formation of the $\gamma$-phase in isotactic polypropene," Polymer, vol. 42, no. 10, pp. 4597-4603, 2001. 
[24] M. Blomenhofer, S. Ganzleben, D. Hanft et al., “"Designer" nucleating agents for polypropylene," Macromolecules, vol. 38, no. 9, pp. 3688-3695, 2005.

[25] M. Obadal, R. Čermák, and K. Stoklasa, "Tailoring of threephase crystalline systems in isotactic poly(propylene)," Macromolecular Rapid Communications, vol. 26, no. 15, pp. 1253-1257, 2005. 

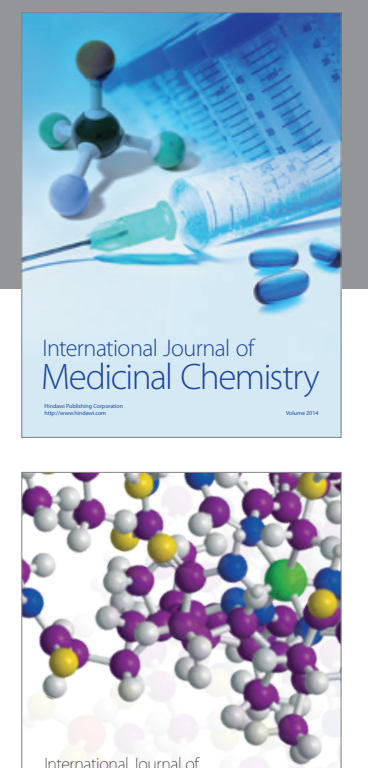

\section{Carbohydrate} Chemistry

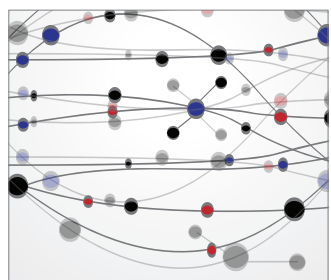

The Scientific World Journal
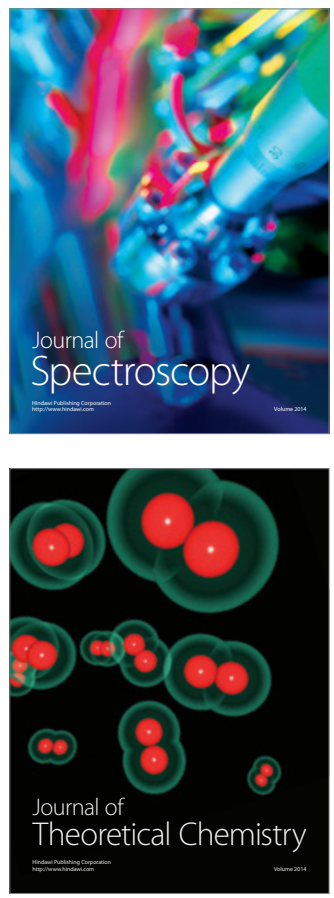
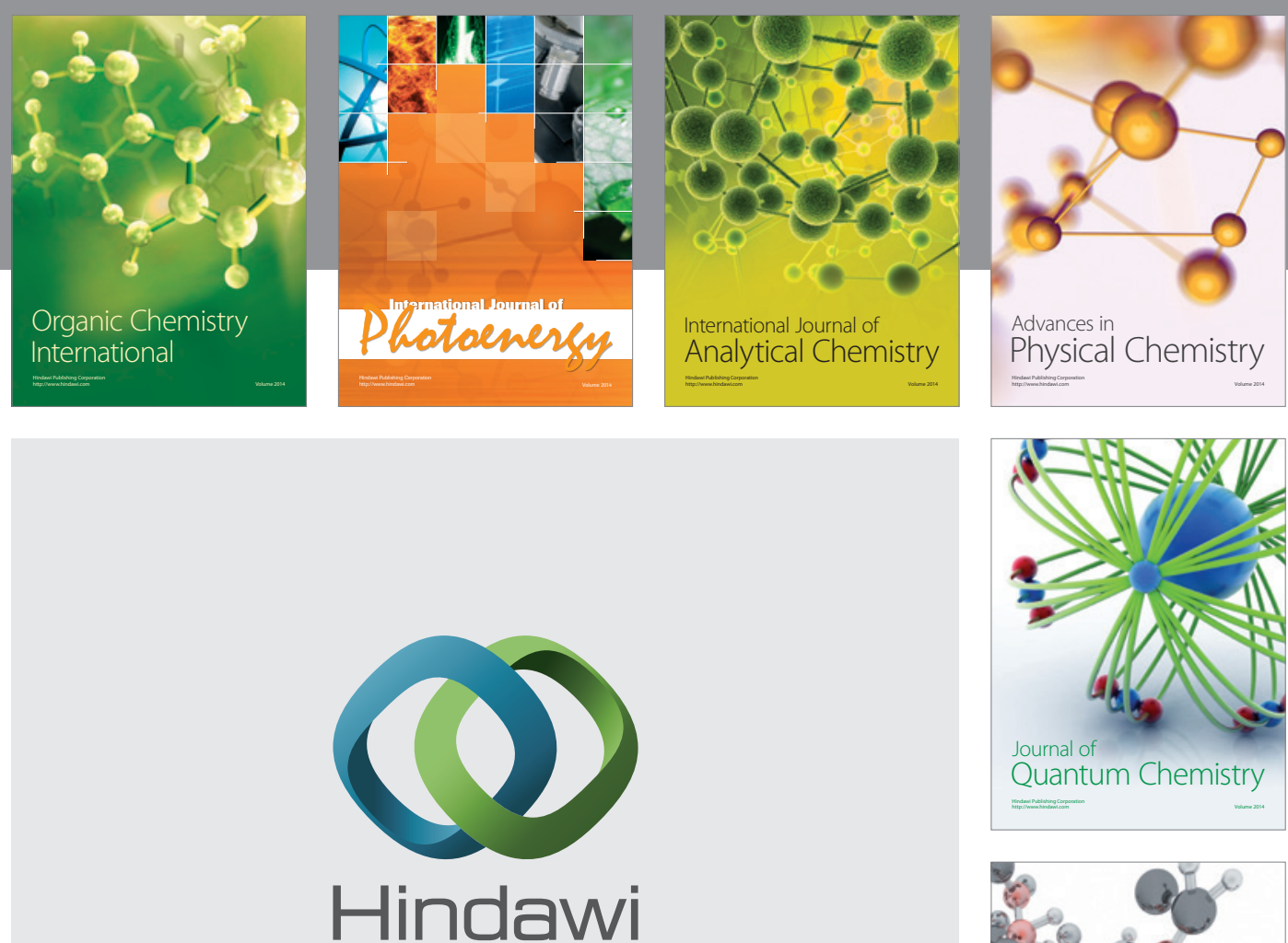

Submit your manuscripts at

http://www.hindawi.com

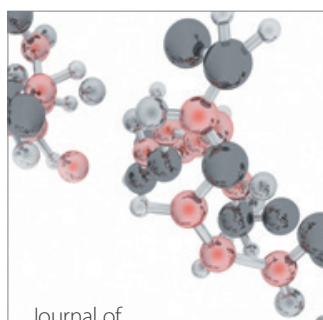

Analytical Methods

in Chemistry

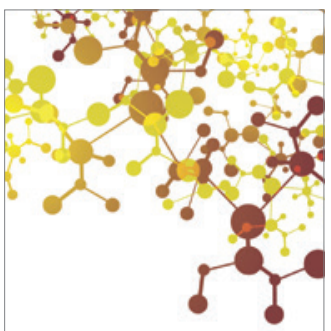

Journal of

Applied Chemistry

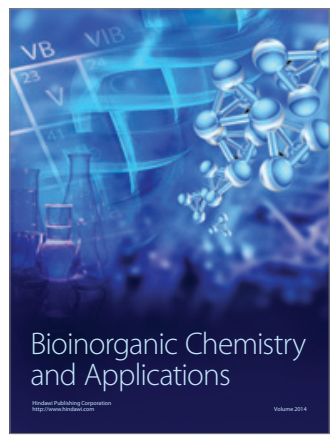

Inorganic Chemistry
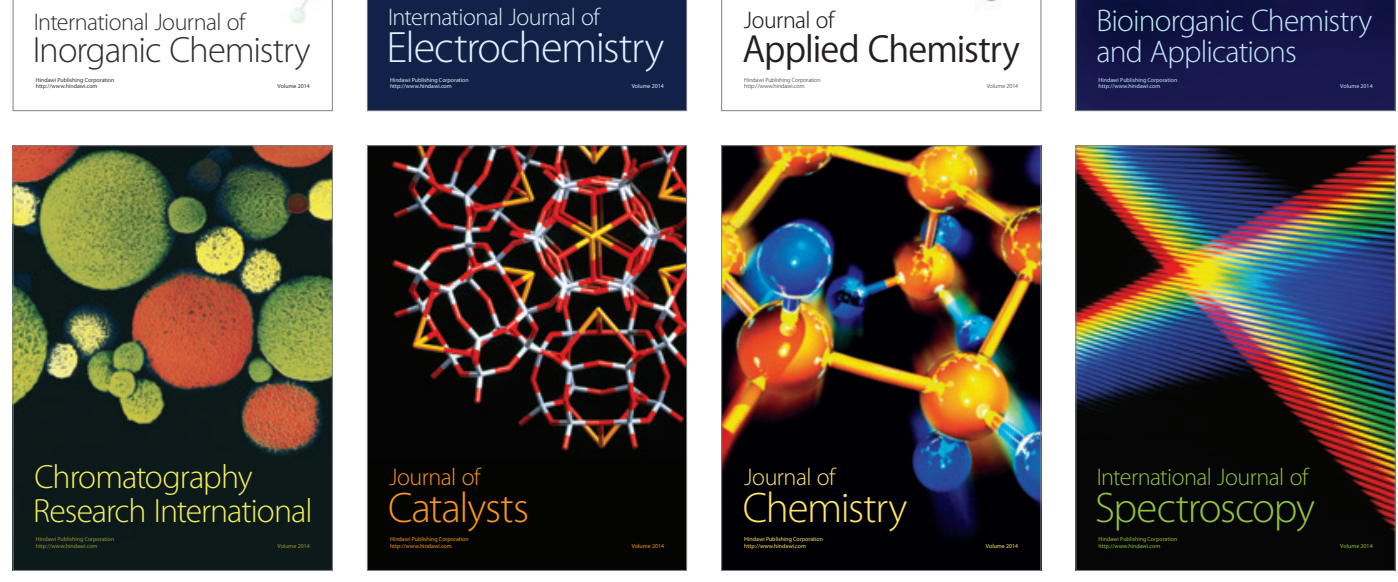